\title{
Systematic Review \\ Nitrosative Stress Molecules in Multiple Sclerosis: A Meta-Analysis
}

\author{
Moritz Förster ${ }^{1,+} \mathbb{D}$, Christopher Nelke ${ }^{1,+}$, Saskia Räuber ${ }^{1} \mathbb{D}$, Hans Lassmann ${ }^{2} \mathbb{D}$, Tobias Ruck ${ }^{1}$, \\ Maria Pia Sormani ${ }^{3,4}$, Alessio Signori ${ }^{3}\left(\mathbb{D}\right.$, Hans-Peter Hartung ${ }^{1,5,6,7}$, Patrick Küry ${ }^{1}$ (D) Sven G. Meuth ${ }^{1,+}$ \\ and David Kremer ${ }^{1, *}$
}

1 Department of Neurology, Medical Faculty, Heinrich Heine University, 40225 Düsseldorf, Germany; moritz.foerster@med.uni-duesseldorf.de (M.F.); christopherjannik.nelke@med.uni-duesseldorf.de (C.N.); saskiajanina.raeuber@med.uni-duesseldorf.de (S.R.); Tobias.Ruck@med.uni-duesseldorf.de (T.R.); Hans-Peter.Hartung@med.uni-duesseldorf.de (H.-P.H.); kuery@uni-duesseldorf.de (P.K.); SvenGuenther.Meuth@med.uni-duesseldorf.de (S.G.M.)

2 Department of Neuroimmunology, Center for Brain Research, Medical University of Vienna, 1090 Vienna, Austria; hans.lassmann@meduniwien.ac.at

3 Department of Health Sciences, University of Genoa, 16121 Genoa, Italy; mariapia.sormani@unige.it (M.P.S.); alessio.signori.unige@gmail.com (A.S.)

4 IRCCS Ospedale Policlinico San Martino, 16121 Genoa, Italy

5 Brain and Mind Center, University of Sydney, Sydney 2006, Australia

6 Department of Neurology, Medical University of Vienna, 1090 Vienna, Austria

7 Department of Neurology, Palacky University Olomouc, 77900 Olomouc, Czech Republic

* Correspondence: David.kremer@med.uni-duesseldorf.de; Tel.: +49-(0)2-1181-08084

+ Contributed equally.

Citation: Förster, M.; Nelke, C.; Räuber, S.; Lassmann, H.; Ruck, T.; Sormani, M.P.; Signori, A.; Hartung, H.-P.; Küry, P.; Meuth, S.G.; et al. Nitrosative Stress Molecules in Multiple Sclerosis: A Meta-Analysis. Biomedicines 2021, 9, 1899. https:// doi.org/10.3390/biomedicines9121899

Academic Editor: María Morell Hita

Received: 7 November 2021

Accepted: 10 December 2021

Published: 14 December 2021

Publisher's Note: MDPI stays neutral with regard to jurisdictional claims in published maps and institutional affiliations.

Copyright: (c) 2021 by the authors. Licensee MDPI, Basel, Switzerland. This article is an open access article distributed under the terms and conditions of the Creative Commons Attribution (CC BY) license (https:// creativecommons.org/licenses/by/ $4.0 /)$.

\begin{abstract}
Multiple sclerosis (MS) is an immune-mediated disease of the central nervous system of unknown etiology. As it is still a diagnosis of exclusion, there is an urgent need for biomarkers supporting its diagnosis. Increasing evidence suggests that nitrosative stress may play a pivotal role in the pathogenesis of MS. However, previous reports supporting the role of nitrosative stress molecules as disease biomarkers are inconsistent overall. We therefore systematically analyzed the existing literature to compare the serum and cerebrospinal fluid (CSF) levels of nitrite/nitrate in MS patients with those in patients with noninflammatory other neurological diseases (NIOND) and healthy controls (HC), respectively. We searched the PubMed database and included original articles investigating nitrite/nitrate levels in MS patients and NIOND patients or HC based on predefined selection criteria. Effect sizes were estimated by the standardized mean difference using a random effects model. Our results suggest that MS is associated with higher nitrite/nitrate levels within the CSF compared with patients with NIOND (SMD of 1.51; 95\% CI: 0.72, 2.30; $p=0.0008$ ). Likewise, nitrite/nitrate in the CSF of MS patients trends towards increased levels compared with those of HC but does not reach statistical significance (SMD of 3.35; 95\% CI: $-0.48,7.19 ; p=0.07$ ). Measurement of nitrite/nitrate in the CSF might be a valuable tool facilitating the differentiation of MS and NIOND. Further studies with more homogeneous study criteria are needed to corroborate this hypothesis.
\end{abstract}

Keywords: multiple sclerosis; biomarker; nitrosative stress; NOx; meta-analysis

\section{Introduction}

Multiple sclerosis (MS) is an immune-mediated inflammatory disease of the central nervous system (CNS) of unclear etiology. It is characterized by inflammatory, demyelinating, and degenerative aspects and can be divided into different subtypes, such as a relapsing-remitting (RRMS), a primary progressive (PPMS), and a secondary progressive (SPMS) form. Pathomechanistically, repeated inflammatory (auto)immune attacks on the CNS lead to oligodendrocyte and myelin sheath damage, resulting in impaired 
axonal signal conduction. Inflammation is mediated by reactive immune cells comprising not only T lymphocytes and B cells but also CNS-resident activated microglia and macrophages [1-3]. Accumulating evidence suggests that oxidative and nitrosative stress molecules produced by immune or CNS-resident cells play a pivotal role in the pathogenesis and progression of MS. These molecules include oxygen and nitrogen radicals, such as superoxide anions $\left(\mathrm{O}^{-}\right)$, hydroxyl radicals $\left(\mathrm{OH}^{-}\right)$, or nitric oxide $(\mathrm{NO})$. $\mathrm{NO}$ contributes to vasodilation and disruption of the blood-brain barrier (BBB), which is one of the core elements of MS histopathology [4]. It facilitates the transmigration of leukocytes into the CNS and fuels continuing inflammation. NO is a volatile gaseous molecule that is only mildly damaging. However, by reacting with $\mathrm{O}_{2}{ }^{-}$, it forms the extremely toxic derivate peroxynitrite $\left(\mathrm{ONOO}^{-}\right)$. Via its oxidative and nitrosative properties, $\mathrm{ONOO}^{-}$damages numerous molecules, such as DNA and lipids, rendering them inoperable [5,6]. Thus, NO is key for demyelination and axonal degeneration by indirectly impairing oligodendroglial energy metabolism via mitochondrial DNA and lipid membrane damage. This ultimately results in oligodendroglial cell death and myelin demise. In addition, NO-mediated protein nitration can activate or inactivate proteins or even cause them to gain new functions [7]. For instance, NO-derived species can activate matrix metalloproteinases (MMPs), which degrade myelin components [8]. Moreover, they can impair the metabolic support of axons through downregulation of the oligodendroglial monocarboxylate transporter 1 (MCT1) [9] or lead to an accumulation of nitrosylated protein residues in MS lesions, such as 3-nitrotyrosine [10,11]. NO is quantifiable in its soluble forms of nitrate or nitrite, which are stored in biofluids, such as the cerebrospinal fluid (CSF) or the serum. This is relevant for the clinician as the CSF is one of the pillars of MS diagnosis and has regained substantial importance since the revision of the McDonald diagnostic criteria in 2017 [12]. In this context, it is important for the clinician to rule out MS mimics, such as noninflammatory other neurological diseases (NIOND) like migraine or small vessel disease. Similar to MS, in these diseases, patients complain of relapsing symptoms and feature white matter lesions on cerebral MR imaging. At times, the unequivocal classification of such lesions can constitute a challenge. Moreover, beyond oligoclonal bands (OCBs) there are no established CSF markers that support the diagnosis of MS, even though the past years have seen the MRZ reaction gain a place as a highly specific diagnostic tool. Therefore, an additional biomarker supporting the diagnosis of MS would be valuable regarding an earlier diagnosis and thus a more efficient treatment. In this regard, several meta-analyses have investigated the potential of various molecules [13-15]. However, the potential of nitrosative stress molecules as disease biomarkers has not yet been systematically investigated. With this meta-analysis, we aim to suggest the measurement of nitrogen species as a tool to better delineate MS from other diseases and healthy conditions.

\section{Materials and Methods}

\subsection{Search Strategy}

This meta-analysis was performed in accordance with the preferred reporting items for systematic reviews and meta-analyses (PRISMA) statement. Peer-reviewed articles in English from the PubMed database were systematically reviewed. The terms used for the database search were "multiple sclerosis" and "nitrate" or "nitrite" or "nitrosative stress" without restriction to the year of publication. Clinical studies were included if data on the mentioned biomarkers for RRMS and NIOND patients and HC were given. Accordingly, studies were not considered if they included data from in vitro or animal experiments. Primary screening of the titles and abstracts was followed by selection of articles being relevant to this study and ensuing full-text scrutiny. Studies with serum and cerebrospinal fluid data were included. For reasons of clinical practicability, two comparison groups were formed for the meta-analysis: NIOND versus RRMS patients and HC versus RRMS patients. In cases where no differentiation of MS subtypes was made, we included all available data given for pooled "MS patients". Moreover, in cases where differentiation was made between "active" and "stable" MS, we only included "active" MS. Studies 
were excluded if (1) no result parameters were given in the text, (2) the study design did not correspond to the envisaged design of a comparison of NIOND versus MS patients or HC versus MS patients and/or the study investigates the effect of a medication, and (3) not nitrites/nitrates but other molecules were investigated, such as NO. To calculate the effective size (ES) for this meta-analysis data of mean biomarker concentration, standard deviation (SD) and sample size were extracted from the included studies. Data on age, sex, disease duration, and expanded disability status scale were extracted as well.

\subsection{Data Extraction}

We extracted data including first author, publication year, study design, number of patients per group, selection of patients and controls, and recorded levels of the nitrosative stress species nitrite and nitrate and the sum of both (NOx).

\subsection{Data Analysis}

Meta-analysis was performed with R 3.5.3 (R Foundation for Statistical Computing, Vienna, Austria) using the metafor package [16]. Heterogeneity was assessed by calculating the $I^{2}$ value [17]. An $I^{2}$ value greater $50 \%$ was considered a high degree of heterogeneity, and a random-effects model was applied [18]. We calculated the pooled effect estimate and $95 \%$ confidence interval (CI) for each between group comparisons. Subgroup analysis was performed for individual nitrosative stress molecules. A $p$-value $<0.05$ was considered statistically significant.

\section{Results}

\subsection{Inclusion of Studies}

Based on our search strategy, we identified 266 studies from the PubMed database. After removing duplicates, the number of records eligible for screening was 211. Out of these, 180 did not meet the inclusion criteria; thus, 31 were further assessed for eligibility (see Methods). Nine studies were excluded due to various reasons (see Figure 1 and Methods). The remaining 22 studies were included in the final analysis. The selection process is illustrated in Figure 1 and further characterized in the Methods Section. Regarding CSF analysis in MS and NIOND patients, 3 studies investigated nitrite levels; 4, nitrate levels; and 12, the sum of both. No study analyzed serum nitrite levels in MS patients compared with NIOND, while 1 study analyzed serum nitrate levels. Four studies analyzed NOx in the same collective (see Table 1). Comparing MS patients with healthy controls (HC), only 1 study analyzed the nitrite and nitrate concentration in the CSF, while 3 studies analyzed NOx in the CSF. Six studies analyzed the serum concentration of NOx in the same collective. Studies separately examining nitrite or nitrate were not available (see Table 2).

\subsection{Study and Patient Characteristics}

The included studies were published between 1995 and 2020. All studies used valid diagnostic criteria for MS, such as the McDonald or Poser criteria. The first comparison group examining nitrite, nitrate, or NOx levels in patients with NIOND and MS comprised 348 MS patients and 310 NIOND patients within the CSF subgroup, while in the serum subgroup, 102 MS patients and 83 NIOND patients were included. The second group comparing MS patients and HC included 80 MS patients and $54 \mathrm{HC}$ in the CSF subgroup, while the serum group comprised $373 \mathrm{MS}$ patients and $410 \mathrm{HC}$. Regarding the analysis technique, $70.8 \%(17 / 24)$ of the studies used Griess reaction, followed by spectrophotometric or semiautomated assays, to measure nitrite and nitrate levels.

\subsection{Nitrosative Stress Molecules in Patients with MS and NIOND}

As elucidated above, for CSF analysis a total of 658 patients (348 MS patients and 310 NIOND patients) from 16 studies were eligible. A random effects model was used due to significant heterogeneity with $I^{2}=87 \%$. Pooled results showed an SMD of 1.51 (95\% CI: $0.72,2.30 ; p=0.0008$; Figure 2A). Our results suggest that MS is associated with higher 
nitrite/nitrate levels within the CSF compared with patients with NIOND. For serum analysis, a total of 185 patients (102 MS patients and 83 NIOND patients) from 5 studies were eligible. Here, a random effects model was used with $I^{2}=78 \%$. Pooled results showed an SMD of 0.30 (95\% CI: $-0.66,1.26 ; p=0.4339$; Figure 2B). In contrast to the results of the CSF analysis, these findings suggest that nitrite/nitrate levels in the serum of MS and NIOND patients do not differ significantly.

Identification of studies via databases and registers

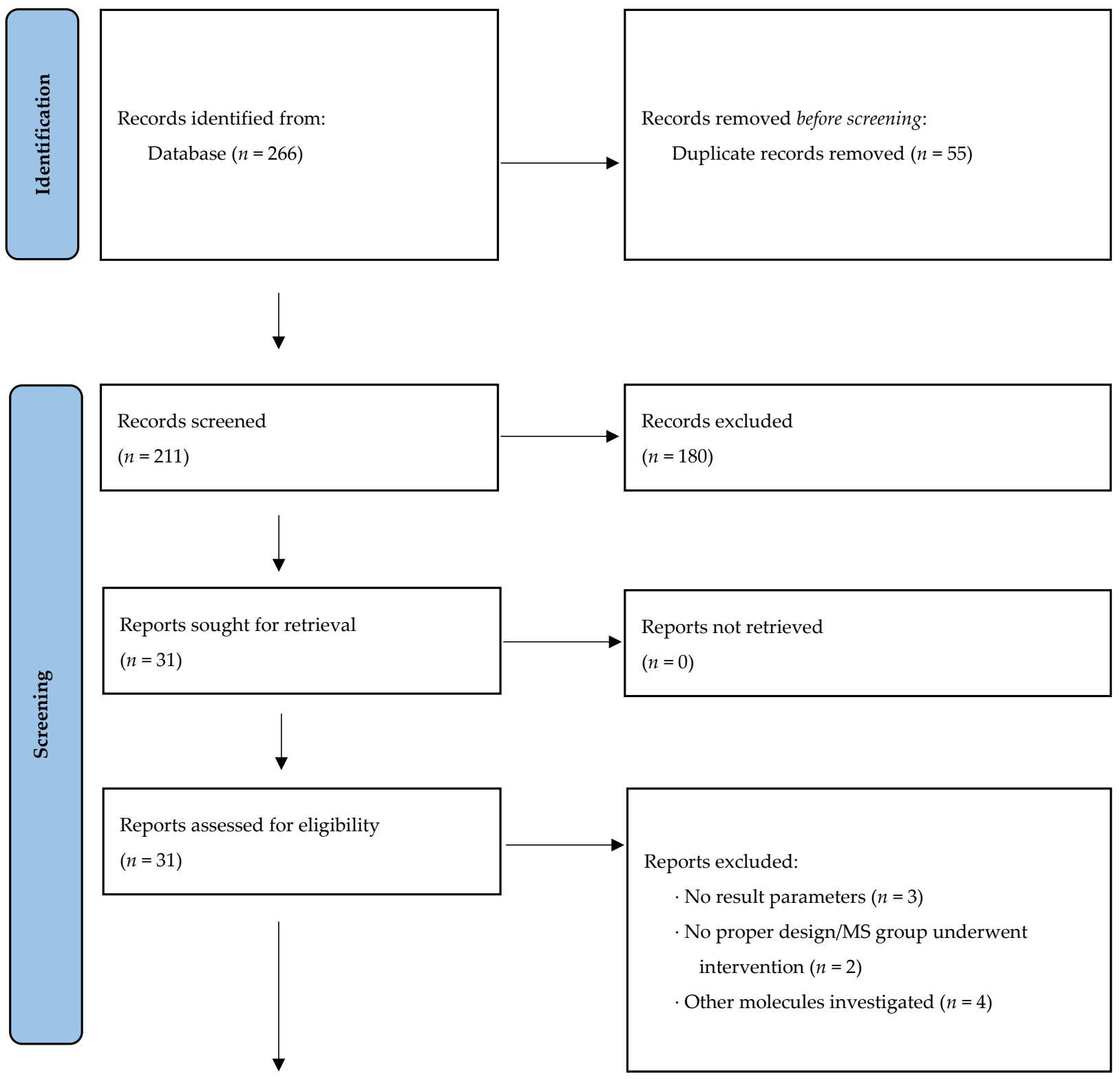

Studies included in review

$(n=22)$

Figure 1. Preferred reporting items for systematic reviews and meta-analyses (PRISMA) study flow diagram. 
Table 1. Characteristics of included studies investigating nitrite and/or nitrate levels in multiple sclerosis patients (MS) versus patients with noninflammatory other neurological diseases (NIOND). CSF = cerebrospinal fluid, NOx = sum of nitrite and nitrate, $\mathrm{C}=$ concentration in $\mu \mathrm{M}, \mathrm{SD}=$ standard deviation, $\mathrm{SEM}=$ standard error of mean, $\mathrm{IQR}=$ interquartile range, $\mathrm{n} / \mathrm{a}=$ data not given or not applicable, $\mathrm{GC}-\mathrm{MS}$ = gas chromatography-mass spectrometry, $\mathrm{DAN}=$ diaminonaphthalene, $\mathrm{a}=$ median (range) ${ }^{\mathrm{b}}=$ mean $(\mathrm{SEM}){ }^{\mathrm{c}}=$ median $(\mathrm{IQR})$.

\begin{tabular}{|c|c|c|c|c|c|c|c|c|c|c|c|c|c|}
\hline \multirow[b]{2}{*}{ Study } & \multirow[b]{2}{*}{ Year } & \multirow[b]{2}{*}{ Specimen } & \multicolumn{5}{|c|}{ MS Patients } & \multicolumn{5}{|c|}{ NIOND Patients } & \multirow[b]{2}{*}{ Assay } \\
\hline & & & $\underset{(\mathrm{m} / \mathrm{f})}{\mathrm{N}}$ & $\begin{array}{c}\text { Mean } \\
\text { Age in } \\
\text { Yrs }( \pm \text { SD) }\end{array}$ & $\begin{array}{l}\text { C Mean } \\
\text { (Nitrite) } \\
( \pm \text { SD })\end{array}$ & $\begin{array}{l}\text { C Mean } \\
\text { (Nitrate) } \\
( \pm \text { SD })\end{array}$ & $\begin{array}{l}\text { C Mean } \\
\text { (NOx) } \\
( \pm \text { SD) }\end{array}$ & $\mathbf{N}(\mathbf{m} / \mathbf{f})$ & $\begin{array}{l}\text { Mean Age } \\
\text { in Yrs } \\
( \pm \text { SD })\end{array}$ & $\begin{array}{l}\text { C Mean } \\
\text { (Nitrite) } \\
( \pm \text { SD })\end{array}$ & $\begin{array}{l}\text { C Mean } \\
\text { (Nitrate) } \\
( \pm \text { SD) }\end{array}$ & $\begin{array}{l}\text { C Mean } \\
\text { (NOx) } \\
( \pm \text { SD) }\end{array}$ & \\
\hline $\begin{array}{l}\text { Cross et al. } \\
\text { [19] }\end{array}$ & 1998 & CSF & $\begin{array}{c}13 \\
(\mathrm{n} / \mathrm{a})\end{array}$ & $\mathrm{n} / \mathrm{a}$ & $9.98(34.6)$ & $47.8(150)$ & $\mathrm{n} / \mathrm{a}$ & 43 (n/a) & $\mathrm{n} / \mathrm{a}$ & $\begin{array}{c}0.64 \\
(1.21)\end{array}$ & $3.01(2.13)$ & $\mathrm{n} / \mathrm{a}$ & $\begin{array}{l}\text { Fluorometric assay } \\
\text { (DAN) }\end{array}$ \\
\hline $\begin{array}{l}\text { Haghikia } \\
\text { et al. [20] }\end{array}$ & 2015 & CSF & $\begin{array}{c}14 \\
(6 / 8) \\
\end{array}$ & $45(9.6)$ & $2.84(0.32)$ & $11.3(0.56)$ & $\mathrm{n} / \mathrm{a}$ & $\begin{array}{c}26 \\
(12 / 14) \\
\end{array}$ & $56.27(15.8)$ & $\begin{array}{c}2.41 \\
(0.11) \\
\end{array}$ & $10.5(0.32)$ & $\mathrm{n} / \mathrm{a}$ & GC/MS \\
\hline $\begin{array}{l}\text { Ikeda et al. } \\
\text { [21] }\end{array}$ & 1995 & CSF & $\begin{array}{c}13 \\
(\mathrm{n} / \mathrm{a})\end{array}$ & $34.6(4.1)$ & $0.62(0.07)$ & $8.3(0.6)$ & $\mathrm{n} / \mathrm{a}$ & $29(\mathrm{n} / \mathrm{a})$ & $54.0(3.8)$ & $\begin{array}{c}0.63 \\
(0.04)\end{array}$ & $7.6(0.7)$ & $\mathrm{n} / \mathrm{a}$ & $\begin{array}{l}\text { Spectrophotometric } \\
\text { assay (Griess) }\end{array}$ \\
\hline \multirow{2}{*}{$\begin{array}{l}\text { de Bustos } \\
\text { et al. [22] }\end{array}$} & \multirow{2}{*}{1999} & CSF & \multirow{2}{*}{$\begin{array}{c}11 \\
(5 / 6)\end{array}$} & \multirow{2}{*}{$36.0(11.3)$} & $\mathrm{n} / \mathrm{a}$ & $6.2(2.3)$ & $\mathrm{n} / \mathrm{a}$ & \multirow{2}{*}{$\begin{array}{c}25 \\
(10 / 15)\end{array}$} & \multirow{2}{*}{$35.4(10.7)$} & $\mathrm{n} / \mathrm{a}$ & $6.9(3.1)$ & $\mathrm{n} / \mathrm{a}$ & \multirow{2}{*}{$\begin{array}{l}\text { Semiautomated } \\
\text { assay (Griess) }\end{array}$} \\
\hline & & serum & & & $\mathrm{n} / \mathrm{a}$ & $22.7(6.4)$ & $\mathrm{n} / \mathrm{a}$ & & & $\mathrm{n} / \mathrm{a}$ & $37.1(23.9)$ & $\mathrm{n} / \mathrm{a}$ & \\
\hline $\begin{array}{l}\text { Seven } \\
\text { et al. [23] }\end{array}$ & 2013 & CSF & $\begin{array}{c}20 \\
(7 / 13)\end{array}$ & $31.0(9.6)$ & $\mathrm{n} / \mathrm{a}$ & $\mathrm{n} / \mathrm{a}$ & $86.28(34.1)$ & $15(6 / 9)$ & $28.33(5.31)$ & $\mathrm{n} / \mathrm{a}$ & $\mathrm{n} / \mathrm{a}$ & $52.52(16.5)$ & $\begin{array}{l}\text { Fluorometric assay } \\
\text { (Sulphanilamide) }\end{array}$ \\
\hline $\begin{array}{l}\text { Drulovic } \\
\text { et al. [24] }\end{array}$ & 2001 & CSF & $\begin{array}{c}57 \\
(\mathrm{n} / \mathrm{a})\end{array}$ & $\mathrm{n} / \mathrm{a}$ & $\mathrm{n} / \mathrm{a}$ & $\mathrm{n} / \mathrm{a}$ & $9.5(1.7)$ & $27(\mathrm{n} / \mathrm{a})$ & $\mathrm{n} / \mathrm{a}$ & $\mathrm{n} / \mathrm{a}$ & $\mathrm{n} / \mathrm{a}$ & $8.7(2.8)$ & $\begin{array}{l}\text { Spectrophotometric } \\
\text { assay (Griess) }\end{array}$ \\
\hline $\begin{array}{l}\text { Brundin } \\
\text { et al. [25] }\end{array}$ & 1999 & CSF & $\begin{array}{c}9 \\
(\mathrm{n} / \mathrm{a})\end{array}$ & $43.1(15.0)$ & $9.3(2.8)^{b}$ & $9.5(1.7)^{b}$ & $15.1(3.1)^{b}$ & $8(2 / 6)$ & $45.0(17.0)$ & $\begin{array}{c}2.3(0.5) \\
b\end{array}$ & $5.2(0.5)^{\mathrm{b}}$ & $7.5(0.5)^{b}$ & $\begin{array}{c}\text { Capillary } \\
\text { electrophoresis }\end{array}$ \\
\hline $\begin{array}{l}\text { Johnson } \\
\text { et al. [26] }\end{array}$ & 1995 & CSF & $\begin{array}{c}10 \\
(\mathrm{n} / \mathrm{a})\end{array}$ & $\mathrm{n} / \mathrm{a}$ & $\mathrm{n} / \mathrm{a}$ & $\mathrm{n} / \mathrm{a}$ & $2.59(0.32)^{b}$ & $10(\mathrm{n} / \mathrm{a})$ & $\mathrm{n} / \mathrm{a}$ & $\mathrm{n} / \mathrm{a}$ & $\mathrm{n} / \mathrm{a}$ & $1.53(0.22)^{b}$ & $\begin{array}{l}\text { Spectrophotometric } \\
\text { assay (Griess) }\end{array}$ \\
\hline \multirow{2}{*}{$\begin{array}{l}\text { Yuceyar } \\
\text { et al. [27] }\end{array}$} & \multirow{2}{*}{2001} & CSF & \multirow{2}{*}{$\begin{array}{c}15 \\
(2 / 13)\end{array}$} & \multirow{2}{*}{$29.93(n / a)$} & $4.85(3.35)$ & $\begin{array}{l}19.64 \\
(5.59) \\
\end{array}$ & $24.54(6.23)$ & \multirow{2}{*}{$\begin{array}{c}15 \\
(5 / 10)\end{array}$} & \multirow{2}{*}{$43.2(19.7)$} & $\begin{array}{c}2.61 \\
(1.77) \\
\end{array}$ & $\begin{array}{l}13.72 \\
(5.17) \\
\end{array}$ & $16.34(5.74)$ & \multirow{2}{*}{$\begin{array}{l}\text { Spectrophotometric } \\
\text { assay (Griess) }\end{array}$} \\
\hline & & serum & & & $5.84(2.86)$ & $\begin{array}{l}35.98 \\
(35.04)\end{array}$ & $41.83(36.41)$ & & & $\begin{array}{c}2.89 \\
(3.31)\end{array}$ & $\begin{array}{l}19.75 \\
(6.62)\end{array}$ & $22.65(7.8)$ & \\
\hline \multirow{2}{*}{$\begin{array}{l}\text { Rejdak } \\
\text { et al. [28] }\end{array}$} & \multirow{2}{*}{2004} & CSF & \multirow{2}{*}{$\begin{array}{c}20 \\
(\mathrm{n} / \mathrm{a})\end{array}$} & \multirow{2}{*}{$\mathrm{n} / \mathrm{a}$} & $\mathrm{n} / \mathrm{a}$ & $\mathrm{n} / \mathrm{a}$ & $11.3(4.9)$ & \multirow{2}{*}{$14(6 / 8)$} & \multirow{2}{*}{$45(23-74)^{a}$} & $\mathrm{n} / \mathrm{a}$ & $\mathrm{n} / \mathrm{a}$ & $6.3(2.3)$ & \multirow{2}{*}{$\begin{array}{l}\text { Spectrophotometric } \\
\text { assay (Griess) }\end{array}$} \\
\hline & & serum & & & $\mathrm{n} / \mathrm{a}$ & $\mathrm{n} / \mathrm{a}$ & $43.8(8.3)$ & & & $\mathrm{n} / \mathrm{a}$ & $\mathrm{n} / \mathrm{a}$ & $36.0(15.9)$ & \\
\hline $\begin{array}{l}\text { Rejdak } \\
\text { et al. [29] }\end{array}$ & 2008 & CSF & $\begin{array}{c}34 \\
(9 / 25)\end{array}$ & $\begin{array}{c}31.0 \\
(20-52)^{\mathrm{a}}\end{array}$ & $\mathrm{n} / \mathrm{a}$ & $\mathrm{n} / \mathrm{a}$ & $8.5 \underset{\mathrm{a}}{(2.5-21.5)}$ & $12(3 / 9)$ & $29(22-50)^{a}$ & $\mathrm{n} / \mathrm{a}$ & $\mathrm{n} / \mathrm{a}$ & $2.5 \underset{a}{(0.9-7.1)}$ & $\begin{array}{l}\text { Spectrophotometric } \\
\text { assay (Griess) }\end{array}$ \\
\hline
\end{tabular}


Table 1. Cont

\begin{tabular}{|c|c|c|c|c|c|c|c|c|c|c|c|c|c|}
\hline \multirow[b]{2}{*}{ Study } & \multirow[b]{2}{*}{ Year } & \multirow[b]{2}{*}{ Specimen } & \multicolumn{5}{|c|}{ MS Patients } & \multicolumn{5}{|c|}{ NIOND Patients } & \multirow[b]{2}{*}{ Assay } \\
\hline & & & $\underset{(\mathrm{m} / \mathrm{f})}{\mathbf{N}}$ & $\begin{array}{c}\text { Mean } \\
\text { Age in } \\
\text { Yrs }( \pm \text { SD) }\end{array}$ & $\begin{array}{c}\text { C Mean } \\
\text { (Nitrite) } \\
( \pm \text { SD) }\end{array}$ & $\begin{array}{c}\text { C Mean } \\
\text { (Nitrate) } \\
( \pm \text { SD) }\end{array}$ & $\begin{array}{c}\text { C Mean } \\
\text { (NOx) } \\
( \pm \text { SD) }\end{array}$ & $\mathbf{N}(\mathbf{m} / \mathbf{f})$ & $\begin{array}{c}\text { Mean Age } \\
\text { in Yrs } \\
( \pm \text { SD) }\end{array}$ & $\begin{array}{c}\text { C Mean } \\
\text { (Nitrite) } \\
( \pm \text { SD) }\end{array}$ & $\begin{array}{c}\text { C Mean } \\
\text { (Nitrate) } \\
( \pm \text { SD) }\end{array}$ & $\begin{array}{c}\text { C Mean } \\
\text { (NOx) } \\
( \pm \text { SD) }\end{array}$ & \\
\hline $\begin{array}{l}\text { Pirrtilä } \\
\text { et al. [30] }\end{array}$ & 2004 & CSF & $\begin{array}{c}8 \\
(1 / 7)\end{array}$ & $28.9(8.9)$ & $\mathrm{n} / \mathrm{a}$ & $\mathrm{n} / \mathrm{a}$ & $1.22(0.17)$ & $\begin{array}{c}25 \\
(7 / 18)\end{array}$ & 47.5 (12.9) & $\mathrm{n} / \mathrm{a}$ & $\mathrm{n} / \mathrm{a}$ & $1.47(0.82)$ & $\begin{array}{l}\text { Spectrophotometric } \\
\text { assay (Griess) }\end{array}$ \\
\hline $\begin{array}{l}\text { Danilov } \\
\text { et al. [31] }\end{array}$ & 2003 & CSF & $\begin{array}{c}24 \\
(6 / 18) \\
\end{array}$ & $\begin{array}{c}43.5 \\
(19-60)^{\mathrm{a}} \\
\end{array}$ & $7.7(1.1)^{b}$ & $9.6(0.7)^{b}$ & $17.3(1.6)^{b}$ & $8(2 / 6)$ & $\begin{array}{c}44.7(26-66) \\
\mathrm{a} \\
\end{array}$ & $\mathrm{n} / \mathrm{a}$ & $5.4(0.3)^{b}$ & $7.4(0.5)^{b}$ & $\begin{array}{c}\text { Capillary } \\
\text { electrophoresis }\end{array}$ \\
\hline $\begin{array}{l}\text { Miljkovic } \\
\text { et al. [32] }\end{array}$ & 2002 & CSF & $\begin{array}{c}50 \\
(13 / 37)\end{array}$ & $35.1(10.6)$ & $\mathrm{n} / \mathrm{a}$ & $\mathrm{n} / \mathrm{a}$ & $9.48(1.98)$ & $23(\mathrm{n} / \mathrm{a})$ & $\mathrm{n} / \mathrm{a}$ & $\mathrm{n} / \mathrm{a}$ & $\mathrm{n} / \mathrm{a}$ & 8.49 (1.33) & $\begin{array}{l}\text { Spectrophotometric } \\
\text { assay (Griess) }\end{array}$ \\
\hline $\begin{array}{l}\text { Giovannoni } \\
\text { et al. [33] }\end{array}$ & 1997 & serum & $\begin{array}{c}21 \\
(5 / 16)\end{array}$ & $40.6(10.7)$ & $\mathrm{n} / \mathrm{a}$ & $\mathrm{n} / \mathrm{a}$ & $74.3(33.7)$ & $14(7 / 7)$ & $47.8(17.8)$ & $\mathrm{n} / \mathrm{a}$ & $\mathrm{n} / \mathrm{a}$ & $41.1(12.3)$ & $\begin{array}{l}\text { Spectrophotometric } \\
\text { assay (Griess) }\end{array}$ \\
\hline $\begin{array}{l}\text { Calabrese } \\
\text { et al. [34] }\end{array}$ & 2002 & CSF & $\begin{array}{c}15 \\
(3 / 12)\end{array}$ & $31.0(7.3)$ & $\mathrm{n} / \mathrm{a}$ & $\mathrm{n} / \mathrm{a}$ & $9.4(1.1)^{\mathrm{b}}$ & $\begin{array}{c}15 \\
(2 / 13)\end{array}$ & $32.4(11.0)$ & $\mathrm{n} / \mathrm{a}$ & $\mathrm{n} / \mathrm{a}$ & $5.2(0.9)^{b}$ & $\begin{array}{l}\text { Spectrophotometric } \\
\text { assay (Griess) }\end{array}$ \\
\hline \multirow{2}{*}{$\begin{array}{l}\text { Sellebjerg } \\
\text { et al. [35] }\end{array}$} & \multirow{2}{*}{2002} & CSF & \multirow{2}{*}{$\begin{array}{c}35 \\
(5 / 30)\end{array}$} & \multirow{2}{*}{$\begin{array}{c}38 \\
(32.0-43.0) \\
c\end{array}$} & $\mathrm{n} / \mathrm{a}$ & $\mathrm{n} / \mathrm{a}$ & $\begin{array}{c}5.5(3.6-9.1) \\
c\end{array}$ & \multirow{2}{*}{$\begin{array}{c}15 \\
(4 / 11)\end{array}$} & \multirow{2}{*}{$\begin{array}{c}45 \\
(45.0-60.0)^{\mathrm{c}}\end{array}$} & $\mathrm{n} / \mathrm{a}$ & $\mathrm{n} / \mathrm{a}$ & $\begin{array}{c}3.3(1.4-4.9) \\
c\end{array}$ & \multirow{2}{*}{$\begin{array}{l}\text { Spectrophotometric } \\
\text { assay (Griess) }\end{array}$} \\
\hline & & serum & & & $\mathrm{n} / \mathrm{a}$ & $\mathrm{n} / \mathrm{a}$ & $\begin{array}{c}34.3 \\
(27.0-47.3)^{\mathrm{c}}\end{array}$ & & & $\mathrm{n} / \mathrm{a}$ & $\mathrm{n} / \mathrm{a}$ & $\begin{array}{c}40.7 \\
(36.5-51.1)^{c}\end{array}$ & \\
\hline
\end{tabular}


Table 2. Characteristics of included studies investigating nitrite and/or nitrate levels in multiple sclerosis patients (MS) versus healthy controls (HC). CSF = cerebrospinal fluid, $\mathrm{NOx}=$ sum of nitrite and nitrate levels, $\mathrm{C}=$ concentration in $\mu \mathrm{M}, \mathrm{SD}=$ standard deviation, $\mathrm{SEM}=$ standard error of mean, IQR $=$ interquartile range, $\mathrm{n} / \mathrm{a}=$ data not given or not applicable, GC-MS = gas chromatography-mass spectrometry, ${ }^{\mathrm{a}}=$ median $($ range $),{ }^{\mathrm{b}}=\mathrm{mean}(\mathrm{SEM})$.

\begin{tabular}{|c|c|c|c|c|c|c|c|c|c|c|c|c|c|}
\hline \multirow[b]{2}{*}{ Study } & \multirow[b]{2}{*}{ Year } & \multirow[b]{2}{*}{ Specimen } & \multicolumn{5}{|c|}{ MS Patients } & \multicolumn{5}{|c|}{$\mathrm{HC}$} & \multirow[b]{2}{*}{ Assay } \\
\hline & & & $\begin{array}{l}N \\
(\mathrm{~m} / \mathrm{f})\end{array}$ & $\begin{array}{c}\text { Mean } \\
\text { Age in } \\
\text { Yrs }( \pm \text { SD) }\end{array}$ & $\begin{array}{c}\text { C Mean } \\
\text { (Nitrite) } \\
( \pm \text { SD) }\end{array}$ & $\begin{array}{c}\text { C Mean } \\
\text { (Nitrate) } \\
( \pm \text { SD) }\end{array}$ & $\begin{array}{c}\text { C Mean } \\
\text { (NOx) } \\
( \pm \text { SD) }\end{array}$ & $N(m / f)$ & $\begin{array}{c}\text { Mean Age } \\
\text { in Yrs } \\
( \pm \text { SD) }\end{array}$ & $\begin{array}{c}\text { C Mean } \\
\text { (Nitrite) } \\
( \pm \text { SD) }\end{array}$ & $\begin{array}{c}\text { C Mean } \\
\text { (Nitrate) } \\
( \pm \text { SD) }\end{array}$ & $\begin{array}{c}\text { C Mean } \\
\text { (NOx) } \\
( \pm \text { SD) }\end{array}$ & \\
\hline $\begin{array}{l}\text { Svenningsson } \\
\text { et al. [36] }\end{array}$ & 1999 & CSF & $\begin{array}{c}12 \\
(\mathrm{n} / \mathrm{a})\end{array}$ & $\mathrm{n} / \mathrm{a}$ & $\begin{array}{c}0.63(0.06) \\
\mathrm{b}\end{array}$ & $\begin{array}{c}8.8(1.1) \\
\mathrm{b}\end{array}$ & $\mathrm{n} / \mathrm{a}$ & $15(\mathrm{n} / \mathrm{a})$ & $\mathrm{n} / \mathrm{a}$ & $\begin{array}{c}0.38 \\
(0.02)^{\mathrm{b}}\end{array}$ & $7.5(1.0)^{b}$ & $\mathrm{n} / \mathrm{a}$ & GC-MS \\
\hline $\begin{array}{l}\text { Rejdak et al. } \\
\text { [37] }\end{array}$ & 2007 & CSF & $\begin{array}{c}20 \\
(6 / 14)\end{array}$ & $\underset{\mathrm{a}}{28(21-46)}$ & $\mathrm{n} / \mathrm{a}$ & $\mathrm{n} / \mathrm{a}$ & $\begin{array}{c}9.1(2.5-21.5) \\
\mathrm{a}\end{array}$ & $10(4 / 6)$ & $29(20-40)^{\mathrm{a}}$ & $\mathrm{n} / \mathrm{a}$ & $\mathrm{n} / \mathrm{a}$ & $2.2 \underset{\mathrm{a}}{(0.9-7.1)}$ & $\begin{array}{l}\text { Spectrophotometric } \\
\text { assay (Griess) }\end{array}$ \\
\hline \multirow{2}{*}{$\begin{array}{c}\text { Acar et al. } \\
\text { [38] }\end{array}$} & \multirow{2}{*}{2003} & CSF & \multirow{2}{*}{$\begin{array}{c}24 \\
(9 / 15) \\
\end{array}$} & \multirow{2}{*}{$30.2(8.3)$} & $\mathrm{n} / \mathrm{a}$ & $\mathrm{n} / \mathrm{a}$ & $11.16(8.6)$ & \multirow{2}{*}{$\begin{array}{c}18 \\
(8 / 10)\end{array}$} & \multirow{2}{*}{$32.0(2.34)$} & $\mathrm{n} / \mathrm{a}$ & $\mathrm{n} / \mathrm{a}$ & $4.32(1.63)$ & \multirow{2}{*}{$\begin{array}{l}\text { Spectrophotometric } \\
\text { assay (Griess) }\end{array}$} \\
\hline & & serum & & & $\mathrm{n} / \mathrm{a}$ & $\mathrm{n} / \mathrm{a}$ & $12.89(7.62)$ & & & $\mathrm{n} / \mathrm{a}$ & $\mathrm{n} / \mathrm{a}$ & $7.42(2.81)$ & \\
\hline $\begin{array}{l}\text { Danilov } \\
\text { et al. [31] }\end{array}$ & 2003 & CSF & $\begin{array}{c}24 \\
(6 / 18) \\
\end{array}$ & $\begin{array}{c}43.5 \\
(19-60)^{\mathrm{a}}\end{array}$ & $7.7(1.1)^{b}$ & $\begin{array}{c}9.6(0.7) \\
\mathrm{b}\end{array}$ & $17.3(1.6)^{\mathrm{b}}$ & $11(3 / 8)$ & $\begin{array}{c}40.0 \underset{\mathrm{a}}{(27-58)} \\
\end{array}$ & $\begin{array}{c}1.9(0.4) \\
\mathrm{b}\end{array}$ & $4.4(0.3)^{\mathrm{b}}$ & $6.2(0.6)^{\mathrm{b}}$ & $\begin{array}{c}\text { Capillary } \\
\text { electrophoresis }\end{array}$ \\
\hline $\begin{array}{l}\text { Oliveira } \\
\text { et al. [39] }\end{array}$ & 2017 & serum & $\begin{array}{l}175 \\
(\mathrm{n} / \mathrm{a})\end{array}$ & $\mathrm{n} / \mathrm{a}$ & $\mathrm{n} / \mathrm{a}$ & $\mathrm{n} / \mathrm{a}$ & $21.68(31.54)$ & $\begin{array}{c}249 \\
(72 / 177)\end{array}$ & 36.7 (10.9) & $\mathrm{n} / \mathrm{a}$ & $\mathrm{n} / \mathrm{a}$ & 45.99 (26.01) & $\begin{array}{l}\text { Spectrophotometric } \\
\text { assay (Griess) }\end{array}$ \\
\hline $\begin{array}{l}\text { Seven et al. } \\
\text { [23] }\end{array}$ & 2013 & serum & $\begin{array}{c}20 \\
(7 / 13) \\
\end{array}$ & $31.0(9.6)$ & $\mathrm{n} / \mathrm{a}$ & $\mathrm{n} / \mathrm{a}$ & $86.28(34.1)$ & $\begin{array}{c}15 \\
(5 / 10) \\
\end{array}$ & $30.2(5.51)$ & $\mathrm{n} / \mathrm{a}$ & $\mathrm{n} / \mathrm{a}$ & 76.61 (21.68) & $\begin{array}{c}\text { Fluorometric assay } \\
\text { (Sulphanilamide) }\end{array}$ \\
\hline $\begin{array}{l}\text { Yuceyar } \\
\text { et al. [27] }\end{array}$ & 2001 & serum & $\begin{array}{c}15 \\
(2 / 13)\end{array}$ & $\begin{array}{l}29.93 \\
(\mathrm{n} / \mathrm{a})\end{array}$ & $5.84(2.86)$ & $\begin{array}{l}35.98 \\
(35.04)\end{array}$ & 41.83 (36.41) & $\begin{array}{c}18 \\
(8 / 10)\end{array}$ & $33.12(5.5)$ & $2.1(3.3)$ & $17.2(4.1)$ & $19.3(3.7)$ & $\begin{array}{l}\text { Spectrophotometric } \\
\text { assay (Griess) }\end{array}$ \\
\hline $\begin{array}{l}\text { Obradovic } \\
\text { et al. [40] }\end{array}$ & 2020 & serum & $\begin{array}{c}59 \\
(24 / 35) \\
\end{array}$ & $40.0(10.2)$ & $\mathrm{n} / \mathrm{a}$ & $\mathrm{n} / \mathrm{a}$ & $4.5(1.5)$ & $\begin{array}{c}88 \\
(36 / 52) \\
\end{array}$ & $38.9(9.0)$ & $\mathrm{n} / \mathrm{a}$ & $\mathrm{n} / \mathrm{a}$ & $2.6(0.9)$ & $\begin{array}{l}\text { Semiautomated } \\
\text { assay (Griess) }\end{array}$ \\
\hline $\begin{array}{l}\text { Giovannoni } \\
\text { et al. [33] }\end{array}$ & 1997 & serum & $\begin{array}{c}21 \\
(5 / 16)\end{array}$ & $40.6(10.7)$ & $\mathrm{n} / \mathrm{a}$ & $\mathrm{n} / \mathrm{a}$ & $74.3(33.7)$ & $\begin{array}{c}22 \\
(11 / 11)\end{array}$ & 33.8 (7.4) & $\mathrm{n} / \mathrm{a}$ & $\mathrm{n} / \mathrm{a}$ & $32.8(12.2)$ & $\begin{array}{l}\text { Spectrophotometric } \\
\text { assay (Griess) }\end{array}$ \\
\hline
\end{tabular}


A

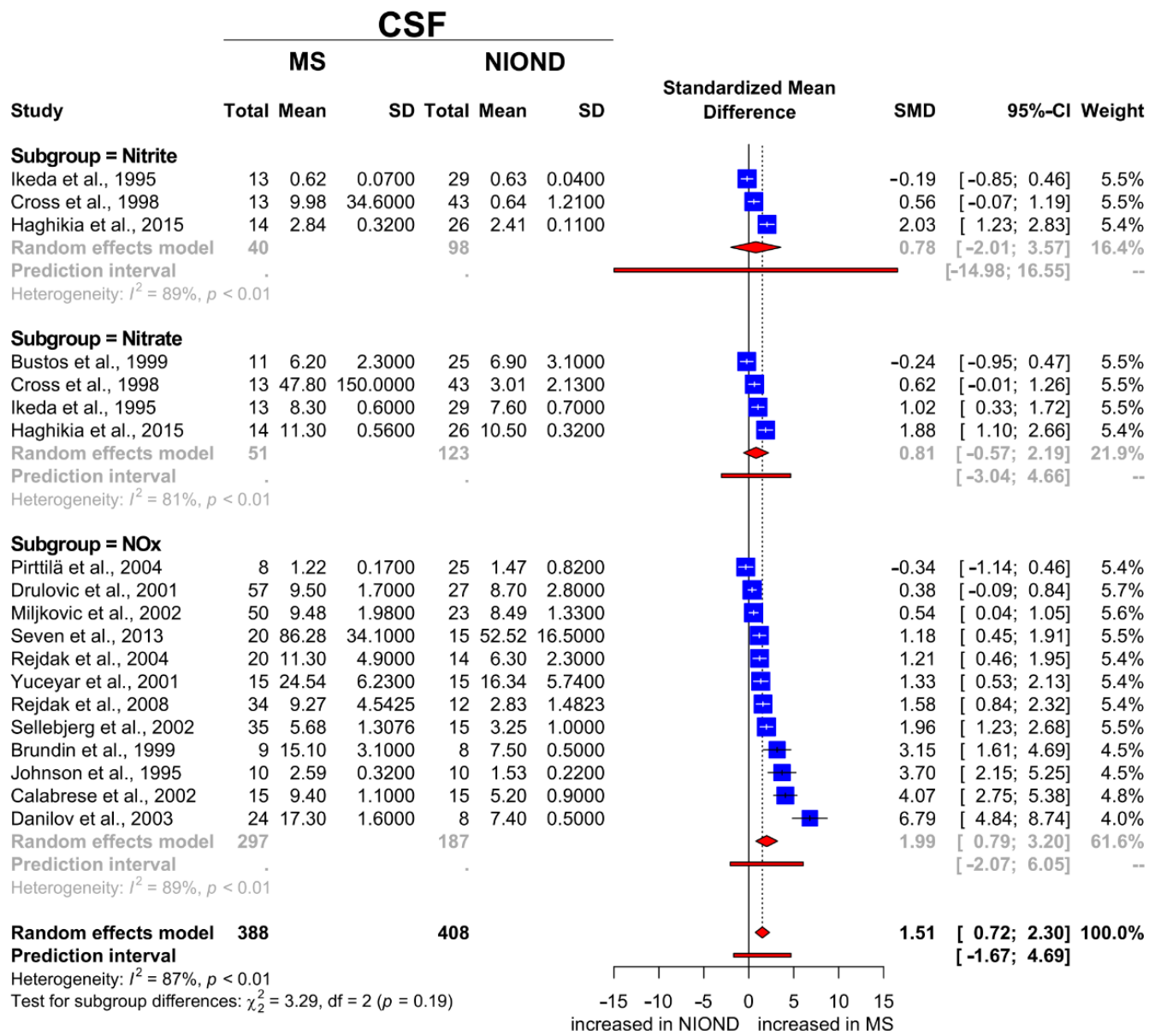

Random effects model SMD $1.510495 \%-\mathrm{Cl}[0.7204 ; 2.3003] t=4.02, p=0.0008$

B

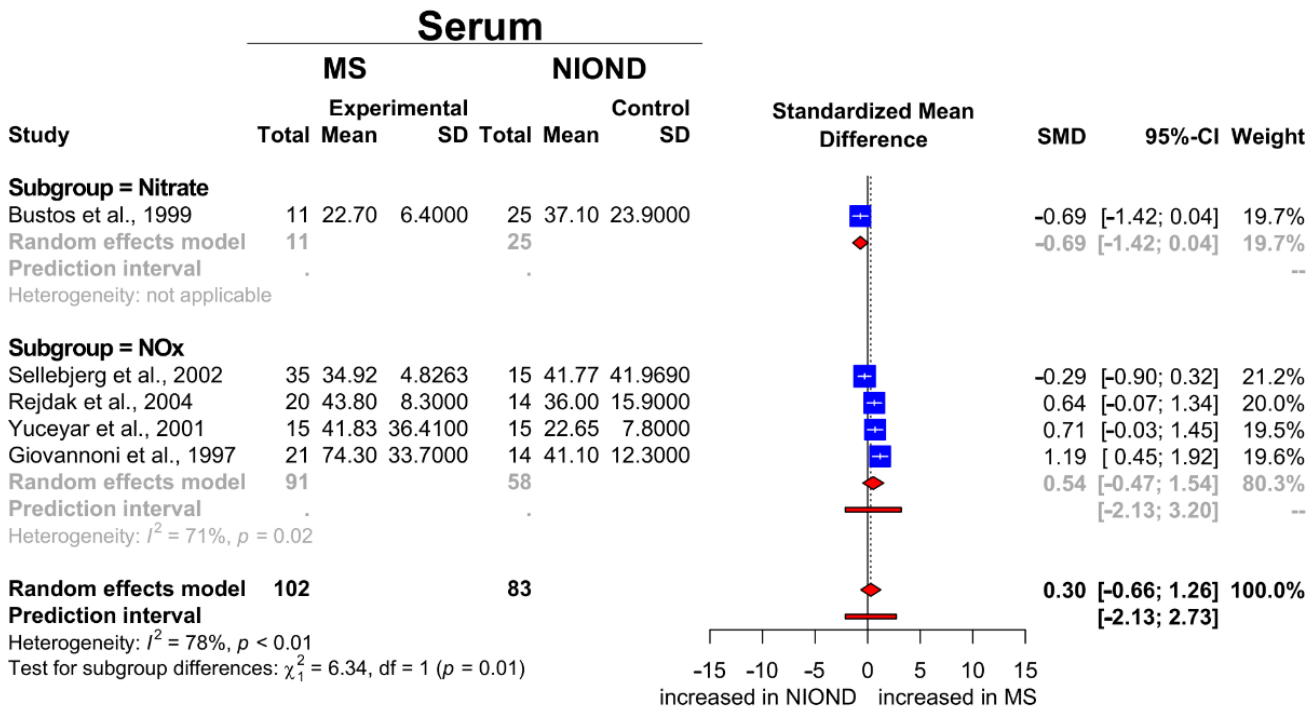

Random effects model SMD $0.300095 \%-\mathrm{Cl}[-0.6584 ; 1.2584] t=0.87, p=0.4339$

Figure 2. Forest plots displaying the meta-analysis for markers of nitrosative stress in (A) the CSF and (B) the serum compartment for MS vs. NIOND, respectively. The dashed vertical line indicates the overall effect, while the solid line indicates the null effect (SMD =0). Abbreviations: CSF = cerebrospinal fluid, NIOND = noninflammatory other neurological disease, $\mathrm{NOx}=$ sum of nitrite and nitrate levels, $\mathrm{MS}=$ multiple sclerosis, $\mathrm{SD}=$ standard deviation, $\mathrm{SMD}=$ standardized mean difference. 


\subsection{Nitrosative Stress Molecules in Patients with MS and HC}

For CSF analysis, a total of 134 participants ( 80 MS patients and $54 \mathrm{HC}$ ) from four studies were eligible. The studies showed significant heterogeneity with $I^{2}=93 \%$, which is why a random effects model was used. There was no statistically significant difference between MS patients and HC, given an SMD of 3.35 (95\% CI: $-0.48,7.19 ; p=0.07$; Figure 3A). Our results suggest that the concentration of nitrite/nitrate in the CSF of MS patients is increased compared with HC but does not reach statistical significance. For serum analysis, a total of 783 participants (373 MS patients and $410 \mathrm{HC}$ ) from six studies were eligible. Pooled results did not show a statistically significant difference between MS patients and HC with an SMD of 0.53 (95\% CI: $-0.67,1.73 ; p=0.3063$; Figure 3B).

A

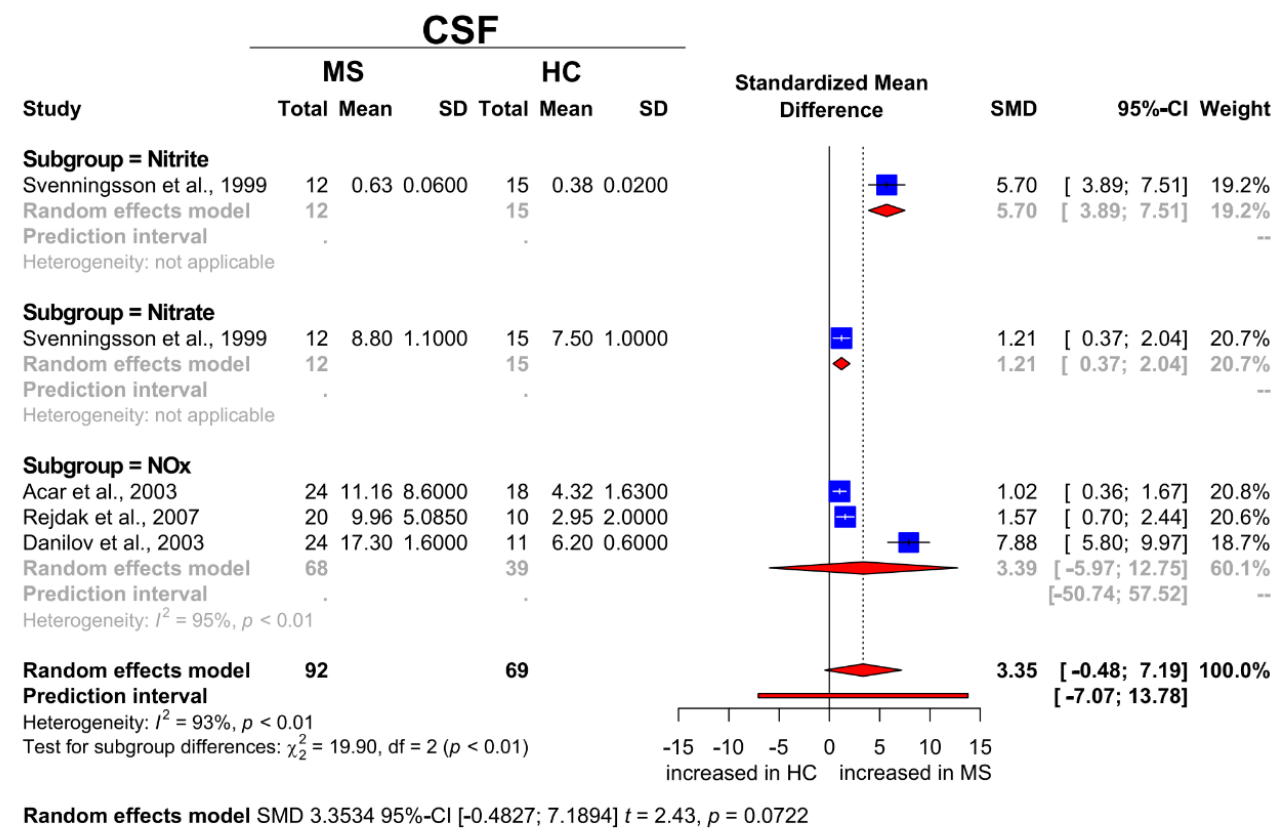

B

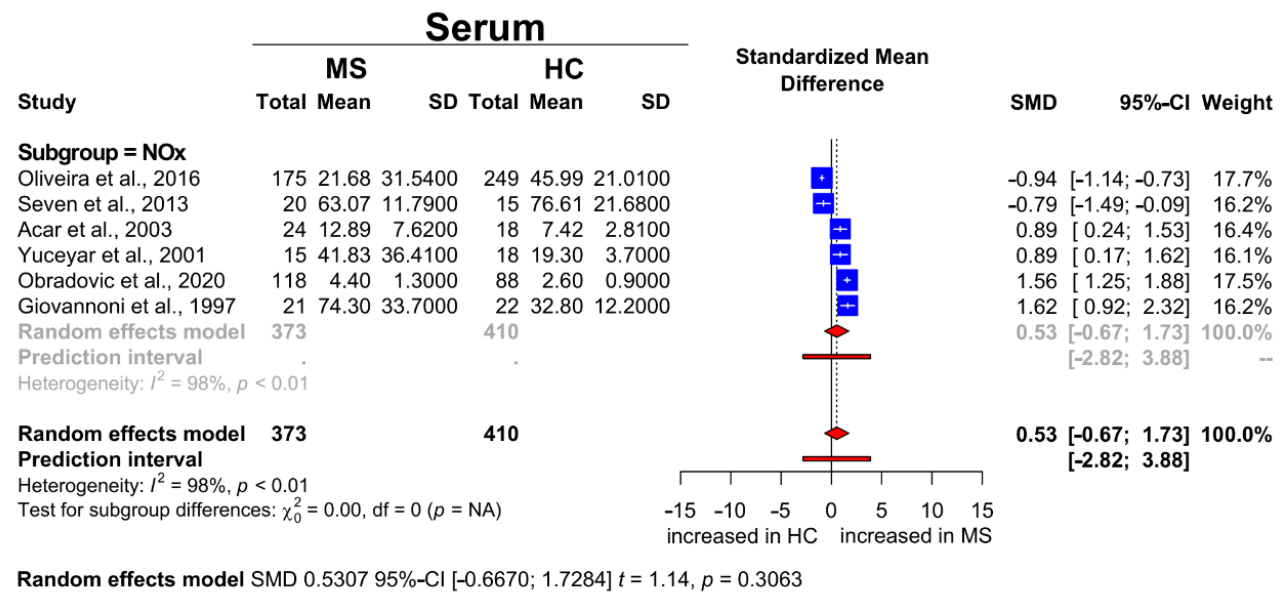

Figure 3. Forest plot displaying the meta-analysis for markers of nitrosative stress in (A) the CSF and (B) the serum compartment for MS vs. HC, respectively. The dashed vertical line indicates the overall effect, while the solid line indicates the null effect $(\mathrm{SMD}=0)$. Abbreviations: $\mathrm{CSF}=$ cerebrospinal fluid, $\mathrm{HC}=$ healthy controls, $\mathrm{NOx}=$ sum of nitrite and nitrate levels, $\mathrm{MS}=$ multiple sclerosis, $\mathrm{SD}=$ standard deviation, $\mathrm{SMD}=$ standardized mean difference. 


\section{Discussion}

As the diagnosis of MS still requires exclusion of disorders with a similar phenotype, the identification of viable biomarkers to improve diagnostic acuity is of great importance. The clinical differentiation between an MS patient with characteristic symptoms and a healthy asymptomatic individual is easy. The opposite is true for symptomatic patients with MS and NIOND. In the past years, nitrosative stress species have gained increasing scientific attention due to their potential prognostic and diagnostic value. However, the use of nitrosative stress markers in the diagnostic workup for MS is hampered by heterogeneous and, at times, even contradictory results from previous studies [39,40], which is why we conducted this meta-analysis. Comparing MS and NIOND, we observed an overall effect for nitrosative stress species in the CSF but not in the serum. It is tempting to speculate that this could point to a compartment effect of nitrosative stress in the CNS. However, it is known that nitrosative stress molecules, such as nitrite and nitrate, readily cross the blood-brain barrier (BBB) [41]. This apparent contradiction might be explained by the overall scarcity of studies providing data on serum levels of nitrosative stress (see Figure 2B). The comparison between MS and HC followed similar trends as MS and NIOND but did not reach statistical significance probably due to the same problem of underpowering. In general, it is worthwhile to more closely analyze the studies we used for this meta-analysis. Our meta-analysis showed high heterogeneity of the selected studies. This heterogeneity arises from the study population (age, gender, ethnic groups), the sample sizes (varying from 17 to 424), and the application of different MS diagnostic criteria, which evolved during the past 25 years. Of note, some studies did not include data of the mean age and the gender ratio. However, none of the studies performed a subgroup analysis evaluating gender-related differences of the reported results. Another aspect worth discussing are the inclusion criteria for the different groups that were compared. Remarkably, the number of patients with PPMS included was very small, and only a few studies focused exclusively on data from patients with PPMS. Many of the studies included both patients with relapsing and progressive disease courses in their "MS group" or did not clearly differentiate the two MS entities. The same is true for NIOND patients and HC. The inclusion criteria for NIOND and HC groups differ widely from study to study, resulting in cohorts of a very diverse spectrum. Some studies only included tension headache patients in their NIOND group [31], while others included patients with spinal cord tumors or trauma, lumbar disc herniations, epilepsy, and brain tumors [32]. Regarding HC, some studies included CSF or serum samples exclusively from asymptomatic volunteers (see Table 2 and/or Figure 3). Other studies included symptomatic patients complaining of headache or oculomotor palsy with normal CSF [34] findings. For this meta-analysis, we therefore reassigned all studies based on their control group, whereby only asymptomatic individuals were considered as $\mathrm{HC}$ and patients with neurological symptoms as NIOND. Beyond the aforementioned aspects, other factors might influence our findings. Both the timepoint of nitrosative stress marker analysis and the presence of an immunomodulatory therapy can influence NOx levels. Accordingly, many of the studies screened determined NOx during relapse and during stable disease and combined the data or did not provide information on the disease stage at all. The same is true regarding treatment. Some studies combine data from therapy-naïve, corticosteroid-treated patients and patients treated with immunomodulatory drugs. Others do not provide any information on treatment. To maintain consistency, we therefore excluded drug intervention studies and preferably included data from MS patients during relapse whenever possible. Furthermore, it should be noted that several different NOx analysis techniques were used, each of them with specific characteristics (see Tables 1 and 2). Some studies analyzed either nitrate or nitrite. Others provided data on NOx but did not report nitrite and nitrate concentrations separately. Therefore, we decided to report the results of nitrite, nitrate, and NOx separately (see Figures 2 and 3).

In summary, the results of our meta-analysis show that in MS patients, NOx is significantly increased in comparison with patients with NIOND. However, the principal exclusion of NIOND is only the first step on the way to the diagnosis of clinically definite 
MS. The most challenging next step is to exclude inflammatory other neurological diseases (IOND). This comprises diagnoses such as Behçet's disease, cerebral vasculitis, acute disseminated encephalomyelitis, brainstem encephalitis, neurosarcoidosis, and connective tissue diseases. Patients with these diseases not only show symptoms and cerebral MRI resembling that of MS patients, but also feature similar CSF findings. Accordingly, the gold standard for an MS biomarker should be its specificity in comparison with IOND, which is mostly missing in the included studies. Future studies will have to address this issue. Translated to clinical practice, our findings argue for including nitrosative stress marker analysis in the CSF workup for MS. In general, CSF analysis has regained the status of a routine procedure since the revision of the McDonald criteria in 2017. In summary, it seems that nitrosative stress molecules in the CSF might be a valuable tool to differentiate MS from NIOND. However, further studies will be needed to corroborate this hypothesis.

Author Contributions: Conceptualization, D.K., H.L. and M.F.; methodology, D.K., M.F. and C.N.; software, C.N.; validation, D.K., M.F. and C.N.; formal analysis, C.N.; investigation, D.K. and M.F.; resources, D.K. and M.F.; data curation, D.K., M.F. and C.N.; writing-original draft preparation, D.K., M.F. and C.N.; writing-review and editing, S.R., H.L., P.K., T.R., M.P.S., A.S., H.-P.H. and S.G.M.; visualization, M.F. and C.N.; supervision, H.-P.H., S.G.M. and D.K.; project administration, S.G.M. and D.K. All authors have read and agreed to the published version of the manuscript.

Funding: This research received no external funding.

Institutional Review Board Statement: Not applicable.

Informed Consent Statement: Not applicable.

Data Availability Statement: Data will be provided on request.

Conflicts of Interest: M.F., C.N., S.R., and A.S. declare no competing interests. H.L. has received fees for lectures from Merck Serono, Novartis, and Sanofi Aventis, and served as a consultant for Biogen Idec, MedDay, and Roche. Research in the laboratory of P.K. was supported by Stifterverband/Novartisstiftung, James and Elisabeth Cloppenburg, Peek and Cloppenburg Düsseldorf Stiftung, and the Christiane and Claudia Hempel Foundation for clinical stem cell research. P.K. received consulting/travel/congress grants from GeNeuro, Sanofi, and Servier. T.R. reports grants from the German Ministry of Education, Science, Research, and Technology; grants and personal fees from Sanofi-Genzyme and Alexion; personal fees from Biogen, Roche, and Teva; and personal fees and nonfinancial support from Merck Serono, outside the submitted work. M.P.S. received consulting fees from Merck, Biogen, Novartis, Sanofi-Genzyme, Roche, Celgene, GeNeuro, GSK, MedDay, and Immunic. Uccelli participated in advisory boards for Biogen and Roche. H.-P.H. has received fees for consulting, speaking, and serving on steering committees from Bayer HealthCare, Biogen Idec, Celgene BMS, CSL Behring, GeNeuro, Genzyme, MedDay, MedImmune, Merck Serono, Novartis, Roche, Sanofi, TG Therapeutics, and Viela Bio with approval by the rector of Heinrich Heine University Düsseldorf. S.G.M. received honoraria for lecturing and travel expenses for attending meetings from Almirall, Amicus Therapeutics Germany, Bayer HealthCare, Biogen, Celgene, Diamed, Genzyme, MedDay Pharmaceuticals, Merck Serono, Novartis, Novo Nordisk, ONO Pharma, Roche, Sanofi-Aventis, Chugai Pharma, QuintilesIMS, and Teva. His research is funded by the German Ministry of Education and Research (BMBF), Bundesinstitut für Risikobewertung (BfR), Deutsche Forschungsgemeinschaft (DFG), Else Kröner-Fresenius Foundation, Gemeinsamer Bundesausschuss (G-BA), German Academic Exchange Service, Hertie Foundation, Interdisciplinary Center for Clinical Studies (IZKF) Muenster, and German Foundation Neurology, and by Alexion, Almirall, Amicus Therapeutics Germany, Biogen, Diamed, Fresenius Medical Care, Genzyme, HERZ Burgdorf, Merck Serono, Novartis, ONO Pharma, Roche, and Teva. D.K. received travel grants from GeNeuro and Merck; refund of congress participation fees from GeNeuro, Merck, and Servier; consulting fees from Grifols; payment for lectures from Grifols; and support for research projects from Teva. 


\section{References}

1. Kremer, D.; Gruchot, J.; Weyers, V.; Oldemeier, L.; Gottle, P.; Healy, L.; Ho Jang, J.; Kang, T.X.Y.; Volsko, C.; Dutta, R.; et al. pHERV-W envelope protein fuels microglial cell-dependent damage of myelinated axons in multiple sclerosis. Proc. Natl. Acad. Sci. USA 2019, 116, 15216-15225. [CrossRef] [PubMed]

2. Prinz, M.; Priller, J. The role of peripheral immune cells in the CNS in steady state and disease. Nat. Neurosci. 2017, 20, 136-144. [CrossRef]

3. Bar-Or, A.; Li, R. Cellular immunology of relapsing multiple sclerosis: Interactions, checks, and balances. Lancet Neurol. 2021, 20, 470-483. [CrossRef]

4. Thiel, V.E.; Audus, K.L. Nitric oxide and blood-brain barrier integrity. Antioxid. Redox Signal. 2001, 3, 273-278. [CrossRef]

5. Zhang, J.; Dawson, V.L.; Dawson, T.M.; Snyder, S.H. Nitric oxide activation of poly(ADP-ribose) synthetase in neurotoxicity. Science 1994, 263, 687-689. [CrossRef]

6. Radi, R.; Beckman, J.S.; Bush, K.M.; Freeman, B.A. Peroxynitrite-induced membrane lipid peroxidation: The cytotoxic potential of superoxide and nitric oxide. Arch. Biochem. Biophys. 1991, 288, 481-487. [CrossRef]

7. Calcerrada, P.; Peluffo, G.; Radi, R. Nitric oxide-derived oxidants with a focus on peroxynitrite: Molecular targets, cellular responses and therapeutic implications. Curr. Pharm. Des. 2011, 17, 3905-3932. [CrossRef]

8. Smith, K.J.; Lassmann, H. The role of nitric oxide in multiple sclerosis. Lancet Neurol. 2002, 1, 232-241. [CrossRef]

9. Tang, X.; Lan, M.; Zhang, M.; Yao, Z. Effect of nitric oxide to axonal degeneration in multiple sclerosis via downregulating monocarboxylate transporter 1 in oligodendrocytes. Nitric Oxide 2017, 67, 75-80. [CrossRef]

10. Bizzozero, O.A.; DeJesus, G.; Callahan, K.; Pastuszyn, A. Elevated protein carbonylation in the brain white matter and gray matter of patients with multiple sclerosis. J. Neurosci. Res. 2005, 81, 687-695. [CrossRef]

11. Kremer, D.; Schichel, T.; Forster, M.; Tzekova, N.; Bernard, C.; van der Valk, P.; van Horssen, J.; Hartung, H.P.; Perron, H.; Kury, P. Human endogenous retrovirus type $\mathrm{W}$ envelope protein inhibits oligodendroglial precursor cell differentiation. Ann. Neurol. 2013, 74, 721-732. [CrossRef]

12. Thompson, A.J.; Banwell, B.L.; Barkhof, F.; Carroll, W.M.; Coetzee, T.; Comi, G.; Correale, J.; Fazekas, F.; Filippi, M.; Freedman, M.S.; et al. Diagnosis of multiple sclerosis: 2017 revisions of the McDonald criteria. Lancet Neurol. 2018, 17, 162-173. [CrossRef]

13. Li, X.; Yuan, J.; Han, J.; Hu, W. Serum levels of Homocysteine, Vitamin B12 and Folate in Patients with Multiple Sclerosis: An Updated Meta-Analysis. Int. J. Med. Sci. 2020, 17, 751-761. [CrossRef]

14. Trotter, A.; Anstadt, E.; Clark, R.B.; Nichols, F.; Dwivedi, A.; Aung, K.; Cervantes, J.L. The role of phospholipase A2 in multiple Sclerosis: A systematic review and meta-analysis. Mult. Scler. Relat. Disord. 2019, 27, 206-213. [CrossRef] [PubMed]

15. Zhang, S.Y.; Gui, L.N.; Liu, Y.Y.; Shi, S.; Cheng, Y. Oxidative Stress Marker Aberrations in Multiple Sclerosis: A Meta-Analysis Study. Front. Neurosci. 2020, 14, 823. [CrossRef]

16. Viechtbauer, W. Conducting Meta-Analyses in R with the metafor Package. J. Stat. Softw. 2010, 36, 1-48. [CrossRef]

17. Higgins, J.P.; Thompson, S.G. Quantifying heterogeneity in a meta-analysis. Stat. Med. 2002, 21, 1539-1558. [CrossRef]

18. Huedo-Medina, T.B.; Sanchez-Meca, J.; Marin-Martinez, F.; Botella, J. Assessing heterogeneity in meta-analysis: Q statistic or I2 index? Psychol. Methods 2006, 11, 193-206. [CrossRef]

19. Cross, A.H.; Manning, P.T.; Keeling, R.M.; Schmidt, R.E.; Misko, T.P. Peroxynitrite formation within the central nervous system in active multiple sclerosis. J. Neuroimmunol. 1998, 88, 45-56. [CrossRef]

20. Haghikia, A.; Kayacelebi, A.A.; Beckmann, B.; Hanff, E.; Gold, R.; Haghikia, A.; Tsikas, D. Serum and cerebrospinal fluid concentrations of homoarginine, arginine, asymmetric and symmetric dimethylarginine, nitrite and nitrate in patients with multiple sclerosis and neuromyelitis optica. Amino Acids 2015, 47, 1837-1845. [CrossRef]

21. Ikeda, M.; Sato, I.; Matsunaga, T.; Takahashi, M.; Yuasa, T.; Murota, S. Cyclic guanosine monophosphate (cGMP), nitrite and nitrate in the cerebrospinal fluid in meningitis, multiple sclerosis and Guillain-Barre syndrome. Intern. Med. 1995, 34, 734-737. [CrossRef] [PubMed]

22. De Bustos, F.; Navarro, J.A.; de Andres, C.; Molina, J.A.; Jimenez-Jimenez, F.J.; Orti-Pareja, M.; Gasalla, T.; Tallon-Barranco, A.; Martinez-Salio, A.; Arenas, J. Cerebrospinal fluid nitrate levels in patients with multiple sclerosis. Eur. Neurol. 1999, $41,44-47$. [CrossRef]

23. Seven, A.; Aslan, M.; Incir, S.; Altintas, A. Evaluation of oxidative and nitrosative stress in relapsing remitting multiple sclerosis: Effect of corticosteroid therapy. Folia Neuropathol. 2013, 51, 58-64. [CrossRef] [PubMed]

24. Drulovic, J.; Dujmovic, I.; Mesaros, S.; Samardzic, T.; Maksimovic, D.; Stojsavljevic, N.; Levic, Z.; Mostarica Stojokvic, M. Raised cerebrospinal fluid nitrite and nitrate levels in patients with multiple sclerosis: No correlation with disease activity. Mult. Scler. 2001, 7, 19-22. [CrossRef]

25. Brundin, L.; Morcos, E.; Olsson, T.; Wiklund, N.P.; Andersson, M. Increased intrathecal nitric oxide formation in multiple sclerosis; cerebrospinal fluid nitrite as activity marker. Eur. J. Neurol. 1999, 6, 585-590. [CrossRef]

26. Johnson, A.W.; Land, J.M.; Thompson, E.J.; Bolanos, J.P.; Clark, J.B.; Heales, S.J. Evidence for increased nitric oxide production in multiple sclerosis. J. Neurol. Neurosurg. Psychiatry 1995, 58, 107. [CrossRef] [PubMed]

27. Yuceyar, N.; Taskiran, D.; Sagduyu, A. Serum and cerebrospinal fluid nitrite and nitrate levels in relapsing-remitting and secondary progressive multiple sclerosis patients. Clin. Neurol. Neurosurg. 2001, 103, 206-211. [CrossRef] 
28. Rejdak, K.; Eikelenboom, M.J.; Petzold, A.; Thompson, E.J.; Stelmasiak, Z.; Lazeron, R.H.; Barkhof, F.; Polman, C.H.; Uitdehaag, B.M.; Giovannoni, G. CSF nitric oxide metabolites are associated with activity and progression of multiple sclerosis. Neurology 2004, 63, 1439-1445. [CrossRef]

29. Rejdak, K.; Petzold, A.; Stelmasiak, Z.; Giovannoni, G. Cerebrospinal fluid brain specific proteins in relation to nitric oxide metabolites during relapse of multiple sclerosis. Mult. Scler. 2008, 14, 59-66. [CrossRef]

30. Pirttila, T.; Vanhatalo, S.; Turpeinen, U.; Riikonen, R. Cerebrospinal fluid insulin-like growth factor-1, insulin growth factor binding protein-2 or nitric oxide are not increased in MS or ALS. Acta Neurol. Scand. 2004, 109, 337-341. [CrossRef]

31. Danilov, A.I.; Andersson, M.; Bavand, N.; Wiklund, N.P.; Olsson, T.; Brundin, L. Nitric oxide metabolite determinations reveal continuous inflammation in multiple sclerosis. J. Neuroimmunol. 2003, 136, 112-118. [CrossRef]

32. Miljkovic, D.; Drulovic, J.; Trajkovic, V.; Mesaros, S.; Dujmovic, I.; Maksimovic, D.; Samardzic, T.; Stojsavljevic, N.; Levic, Z.; Mostarica Stojkovic, M. Nitric oxide metabolites and interleukin-6 in cerebrospinal fluid from multiple sclerosis patients. Eur. J. Neurol. 2002, 9, 413-418. [CrossRef]

33. Giovannoni, G.; Heales, S.J.; Silver, N.C.; O’Riordan, J.; Miller, R.F.; Land, J.M.; Clark, J.B.; Thompson, E.J. Raised serum nitrate and nitrite levels in patients with multiple sclerosis. J. Neurol. Sci. 1997, 145, 77-81. [CrossRef]

34. Calabrese, V.; Scapagnini, G.; Ravagna, A.; Bella, R.; Foresti, R.; Bates, T.E.; Giuffrida Stella, A.M.; Pennisi, G. Nitric oxide synthase is present in the cerebrospinal fluid of patients with active multiple sclerosis and is associated with increases in cerebrospinal fluid protein nitrotyrosine and S-nitrosothiols and with changes in glutathione levels. J. Neurosci. Res. 2002, 70, 580-587. [CrossRef]

35. Sellebjerg, F.; Giovannoni, G.; Hand, A.; Madsen, H.O.; Jensen, C.V.; Garred, P. Cerebrospinal fluid levels of nitric oxide metabolites predict response to methylprednisolone treatment in multiple sclerosis and optic neuritis. J. Neuroimmunol. 2002, 125, 198-203. [CrossRef]

36. Svenningsson, A.; Petersson, A.S.; Andersen, O.; Hansson, G.K. Nitric oxide metabolites in CSF of patients with MS are related to clinical disease course. Neurology 1999, 53, 1880-1882. [CrossRef] [PubMed]

37. Rejdak, K.; Petzold, A.; Kocki, T.; Kurzepa, J.; Grieb, P.; Turski, W.A.; Stelmasiak, Z. Astrocytic activation in relation to inflammatory markers during clinical exacerbation of relapsing-remitting multiple sclerosis. J. Neural Transm. 2007, 114, 1011-1015. [CrossRef] [PubMed]

38. Acar, G.; Idiman, F.; Idiman, E.; Kirkali, G.; Cakmakci, H.; Ozakbas, S. Nitric oxide as an activity marker in multiple sclerosis. J. Neurol. 2003, 250, 588-592. [CrossRef]

39. Oliveira, S.R.; Kallaur, A.P.; Reiche, E.M.V.; Kaimen-Maciel, D.R.; Panis, C.; Lozovoy, M.A.B.; Morimoto, H.K.; Maes, M.; Dichi, I.; Simao, A.N.C. Albumin and Protein Oxidation are Predictors that Differentiate Relapsing-Remitting from Progressive Clinical Forms of Multiple Sclerosis. Mol. Neurobiol. 2017, 54, 2961-2968. [CrossRef]

40. Obradovic, D.; Andjelic, T.; Ninkovic, M.; Dejanovic, B.; Kotur-Stevuljevic, J. Superoxide dismutase (SOD), advanced oxidation protein products (AOPP), and disease-modifying treatment are related to better relapse recovery after corticosteroid treatment in multiple sclerosis. Neurol. Sci. 2020, 42, 3241-3247. [CrossRef]

41. Giovannoni, G.; Heales, S.J.; Land, J.M.; Thompson, E.J. The potential role of nitric oxide in multiple sclerosis. Mult. Scler. 1998, 4, 212-216. [CrossRef] [PubMed] 